\title{
The Dialogue of Russia and Kazakhstan on Strategic Partnering in Tourism
}

\author{
Lyazat Karimova*, and Klara Kudaibergenova \\ Kokshetau University named after Abay Myrzakhmetov, Kokshetau, Kazakhstan
}

\begin{abstract}
The paper shows problems of the economic, political, social, and cultural relations between Russia and Kazakhstan which are important for the sustainable development of both countries. In particular, it is necessary to create and develop border and inland resort areas and destinations, to introduce an integrated transport system and interstate structures to manage tourist flows as well as to regulate issues emerging in this area. All these will require significant joint efforts of specialists from various spheres. The expected results imply significant progress in the economic and social development of the border and inland regions or settlements involved in corresponding programs and projects as well as a significant increase in the level and quality of life.
\end{abstract}

\section{Introduction}

Nowadays, tourism is not only the most important sector of the global economy. The UN General Assembly proclaimed that the 21 st century is a century of sustainable development, with tourism being its integral part [1]. Besides, the World Tourism Organization (UNWTO) recognizes the significant role of tourism in strengthening intercultural understanding and mutual respect [2]. The Republic of Kazakhstan and the Russian Federation have long been full members of the UNWTO (since 1993 and 1992, respectively) and support its decisions.

After the collapse of the Soviet Union, both Russia and Kazakhstan faced the same problems in the economy which hampered the tourism industry. The economic crisis in the considered countries caused a difficult financial situation and a low standard of living for the population. Moral and physical depreciation and underdevelopment of the tourist infrastructure required large investments. Nevertheless, both countries have always recognized the key role of tourism in their development, and one of the governmental priorities was and still is the sustainable development of this industry.

Today, cooperation between Russia and Kazakhstan in the sphere of tourism is gradually reaching a new level. The emerging opportunities for tourism development between Russia and Kazakhstan were discussed. The relations between Kazakhstan and Russia increasingly face the necessity to intensify bilateral cooperation in the sphere of tourism. It should be noted that every year businesses of both countries demonstrate an increasing interest in sports and tourism as both areas belong to the non-productive sphere

\footnotetext{
*Corresponding author: lyazat-1978@mail.ru
} 
that generates significant revenues and has become a special and rapidly developing industry [3]. At the same time, today Russia and Kazakhstan (together with Belarus) act together as the basis of the post-Soviet space, and they are called the locomotive of integration for good reason [4]. The development of tourism has a significant impact on the formation of the level and quality indicators of life of the population of the country or region. The variety of forms and types of the tourism activities and the high multiplicative effect characteristic for tourism allow simultaneously developing cooperation in the tourism sector [5].

The abovementioned indicates that building a strategic dialogue and cooperation between the two countries in the tourism sector is of the highest priority. This will entail similar positive changes in other sectors and spheres. In the economy, this is expected to lead to a mutual multiplier effect which is extremely necessary now given the rather hard social and economic situation both in the countries in question and the world.

\section{Methods and methodology}

To obtain the information necessary for the preparation of this paper the following methods were used:

1. Theoretical analysis of scientific works, trends, and concepts that are directly related to the problems of intercountry tourism, cross-border cooperation, and the development of intercultural relations and communications.

2. Analysis of official statistical data describing the forms, volumes, and rates of the development of the cooperation in the field of tourism between Kazakhstan and Russia.

3. Study of normative and legal documents of all levels that somehow regulate domestic and international activities in the field of intercountry tourism as well as policy documents that determine the main lines of this activity for a certain period.

4. A comprehensive analysis of some of the activities or programs being implemented or planned for the implementation in the field of tourism between the two countries, both at the governmental level and the level of individual regions, settlements or resort areas of Kazakhstan and Russia.

\section{Results and Discussion}

Tourism has emerged as a vital industry, characterized by a significant effect of growth in income and employment, foreign exchange earnings, and the growth of other sectors, which also determines the development of communications and infrastructure. In most countries of the world, tourism is a priority sector of the economy and the subject of regional development programs between partner countries [6].

Before discussing the problems of interregional tourism development, it is necessary to determine the theoretical foundations of the typology of regional development and scientific approaches to interregional development in the context of tourist space. When considering the peculiarities of the regional development typology, it is an integral part of the regional policy and is a systematization of the aggregated criteria that differ in the scope of public involvement, a centralized or decentralized context for the implementation of regional policy, a macroeconomic and microeconomic level of application, inter- and intraregional focus, and the content of subsequent changes such as redistribution of labour or capital, the endogenous or exogenous nature of the resources of regional development, and the planned level of technological progress. The elaboration of regional policies is made according to the typology of regions. To develop a typology of regions is a very difficult challenge regardless of the criteria used (economic, administrative, geographical, 
social, cultural, historical, environmental, etc.) and the lack of an absolute satisfactory methodology makes the compromise inevitable.

According to the classical method to conceptualize regions, there are three region types:

- homogeneous regions in terms of some unified key criteria, in particular, economic ones (for example, similar per capita income, dominant industrial sector, relatively homogeneous unemployment rate); geographic ones (similar topography or similar climate, common natural resources); and socio-political ones (a certain regional 'identity', a common historical development);

- nodal (polarized) regions characterized by a minimum interest for uniformity, the cohesion being the result of internal flows, relationships, and interdependencies polarized usually towards a dominant center (node);

- regions for planning (programming), whose unity is derived from a certain institutional and administrative framework, and the implementation of some specific policies and programs of the regional development.

The specific character of the regional typology is determined primarily by the role of the regions in the development of adequate regional development policies depending on certain characteristics [7]. In the regional development studies, the criteria for identifying regions are the gross domestic product (GDP) per capita, the regional GDP as compared to the national level, or the growth rate of GDP per capita at the regional level, compared to the national rate of growth.

At the stage of collecting materials for the study, the problem of information support for Kazakh-Russian relations in the tourism sector was identified. Statistics on the thematic section of tourism in the Agency of the Republic of Kazakhstan are presented in the framework of information received from travel agencies only. At the same time, the flows of tourists travelling on their own are not taken into account. The Tourist Information System developed in 2011 by the Ministry of Industry and New Technologies in conjunction with the National Security Committee of the Republic of Kazakhstan is designed to coordinate the movement of tourists but has not yet been put into effect.

Since the subject of the study is the Kazakh-Russian relations in the tourism sector, which are international, as well as in connection with the transition of both countries to international statistical standards, international documents should be guided in determining the category of "tourist". According to the International Recommendations on Tourism Statistics developed by the United Nations (UN) (Basu, Marg, 2010), a visitor is a traveller who travels to a primary destination outside his / her usual environment for less than a year for any main purpose (business trip, vacation or other personal purposes), except for employment in an enterprise registered in the country or place of visit. Such trips made by visitors qualify as tourist trips. Thus, the concept of tourism is a subcategory of the concept of travel, and the concept of visitors is a subcategory of the concept of travellers. Such differences are crucial for collecting data on flows of travellers and visitors and for ensuring the reliability of tourism statistics.

In the development of the travel and tourism industry, an important role belongs to tourism planning [5]. The problem that appears is to identify how the touristic plans can be made and how they can be implemented. It is relevant to determine techniques and processes at the national and regional levels that can be followed to ensure sustainable tourism development. The experience shows that tourism planning produces sustainable positive results. The tourism planning implies the limitation of socially, environmentally, and economically negative effects as well as obtaining positive effects by achieving objectives set.

In the leisure domain, as in others, the planning should provide the best solutions to satisfy the specific demand of customers [8]. In this process, four stages are essential: 
- determination of the current situation at the moment when the planning process is made;

- determination of the desired situation;

- determination of the difference between the current situation and the desired situation, and the establishment of requirements;

- determination of concrete actions to be done eliminate this difference and achievement of objectives set [9].

The first stage implies the development of an accurate description of the current situation at the time of planning. It involves the determination of available material (physical), financial, and human resources and their use in the system of tourism service production, systematization of the services offered and used, and the study of customer behaviour and habits in the leisure industry. Determination of the actual level of demand for leisure services is, in fact, the first useful stage to specify services offered as well as the resources required to develop the practice of desired activities.

Determination of the difference between the current situation (effective behaviour) and desired situation on the consumption of the services in the leisure industry allows identifying leisure needs of customers. The implementation of some measures to eliminate this difference is made after the verification and comparison of the observations obtained by different methods of demand analysis. In the process of planning of the development of the leisure industry, it is necessary to develop a plan or policy where the means and strategies for meeting the customers' needs for recreational services will be presented. This document should identify the adequate actions and relationships between the service providers and the public to promote the better use of resources available to local communities [6].

It is worth mentioning that in tourism regional development planning, two steps are extremely necessary: the implementation of the development plan and its harmonization with the regional tourism development policy. Plans / programs of the regional economic and social development are implemented at two levels: at the national level which also includes the regional development, and at the regional level which implies the development of plans for each region. To adequately and effectively respond to the challenges of today's tourism markets, it is necessary to remember about possible limitations that one city, one country, or one region can have. Therefore, of course, it is necessary to develop and promote cross-border cooperation between Kazakhstan and Russia in the tourism sphere through comprehensive, deliberate, and strategic study of the adjacent regions as a united attractive destination, emphasizing the respective roles of the countries, cities, regional infrastructure networks, administrative bodies, and the private sector.

The documents reviewed propose two stages for the implementation of the program mentioned above: for 2011-2014, it was planned to implement pilot projects for the development of tourist and auto-tourist clusters whereas for 2015-2018, it was planned to promote tried and tested solutions and mechanisms. All clusters planned have been created and are being developed providing additional jobs and increasing tourist flows. Clusters are used to build modern comfortable hotels, campsites, cafes, and restaurants, car parks, sports, entertainment and shopping facilities, and other supporting infrastructures. Further support of the investment projects for the development of tourist clusters in advanced regions of the Russian Federation on a competitive basis is planned, and certain capital investments from the federal budget, budgets of the constituent entities of the Russian Federation, local budgets and active attraction of extrabudgetary sources and private investments, are implied.

We failed to find a concrete legal and regulatory document that would directly prescribe the actions of the customs officials, and the unofficial explanation of this fact is that food, alcohol, and tobacco are much cheaper in Kazakhstan, therefore, such measures serve to 
prevent unauthorized import and export of products without proper clearance. Of course, borders that are open for the movement of goods threaten, first of all, the economic development of both countries, even much more than their security, given the friendly relations that have developed between the countries. But this situation certainly complicates the development of intercountry tourism.

In any case, the strategy of integrating the economies and, in particular, the transport systems of Russia not only with Kazakhstan but also with other countries of the former Union of Soviet Socialist Republics that are strategic partners, will never be fully achieved without a responsible solution of the common issues such as the creation of interstate transport regulation organizations alongside with the information exchange channels, common database and monitoring systems (if, for example, a large-scale monitoring system such as Platon is used in the territory of one of the two countries, a rational scheme of the operational transition to new traffic conditions at border crossings should be at least ensured). Besides, the unity of the strategies for the development of transport systems at the interstate level should be provided.

Much attention should be given to the specific features of the technical aspects of transportation and their elements: the delivery of a vehicle, its loading and unloading, the actual transportation process, the processes of information exchange, the resolution of contentious issues, the distribution of responsibilities, etc. All the factors that slow down the flow process in logistics are usually called 'bottlenecks' and, speaking of the road transport, its significant advantages are precisely the relatively high speed, manoeuvrability, and availability. However, motor transport is also the most sensitive to the spread and negative impact of the 'bottlenecks' and if the issue of ensuring an unhindered environment for its functioning remains unsolved, the motor transport is the most common mode of transport can lose its consumer value significantly which will greatly slow down the development of the intercountry tourism between Russia and Kazakhstan [10].

\section{Conclusions}

Tourism is a 'passport to the world'; it develops mutual understanding, eliminates prejudices, and creates an international environment of mutual friendship and cooperation. International cooperation in the field of tourism has a clear tendency for further improvement which undoubtedly will have a positive effect on the overall development of this sector. Cooperation between the border regions of Russia and Kazakhstan in the sphere of tourism can be developed in the following lines:

- development of information and advertising activities to promote tourism potential of the territories;

- development of exhibition activities;

- development of cross-border tour programs "Asia-Pacific countries - Russia Kazakhstan", including cross-border ring tours "China - Russia - Kazakhstan - China";

- conducting joint scientific researches in the field of tourism as the border regions of Russia and Kazakhstan face similar problems in the development of the international tourism and it will be much easier to solve them together; these problems, as already mentioned, concern the usage of tourism as a channel for illegal labour activities, transporting small-scale consignments of commercial cargo across the border as tourist luggage, etc.;

- development of cooperation in the sphere of tourism education and training of specialists for the tourism and hospitality industry.

The implementation of these and other forms of interaction in the sphere of tourism can become a multiplier of the development of the international cooperation between Russia 
and Kazakhstan. The following specific steps should also be considered to turn the plans into reality:

- to effectively promote various types of available tourism resources, more attention should be paid to preserving the nature, culture, traditions, and the way of life of local communities;

- to revise the traditional methods of promotion of tourist destinations and assess their impact on cross-border cooperation between Russia and Kazakhstan in the tourism sector, more effective PR campaigns with the cooperation of states, cities and regions, the public and private sectors should be implemented;

- to formulate interregional development plans, tourism should be integrated with the specialization of local sectors of economies and activities;

- to develop joint interstate tourist routes between cities and regions and promote the development of tourism that would meet the tourist needs at present, and promote cooperation between the two countries.

In conclusion, it should be noted that the growing interest and attention to tourism recently make the solution for the problem of intercultural communication that penetrates all spheres of life of the modern community, urgent. This requires the education of the host community (through the media, education, science, means of culture), aimed at the development of respect, tolerance, and a spirit of hospitality towards the representatives of other cultures. The solution of this ambitious challenge is impossible without the full involvement of all mechanisms and resources that are only available to the two countries. These opportunities are enormous and only the political will and desire are necessary to realize them.

\section{References}

1. V. Jeremic, Sustainable development the «overriding challenge» of 21st century (2013)

2. Tourism can strengthen intercultural understanding, concludes UNWTO Conference (2012)

3. I. T. Balabanov, Economy of tourism (2001)

4. N. Nazarbayev, Rossiyskaya Gazeta (2010)

5. V. N. Yakunin, West-Russia-East, 8 (2014)

6. K. Basu, V. S. Marg, Impact of Political Instability and Terrorism in the Tourism Industry of Three Middle-East Countries: An Econometric Explorational (2010)

7. V. Nicolae, D. Constantin, Bazele economiei regionale si urbane (1998)

8. M. Yu. Layko, Ye. L. Ilyina, A. N. Latkin, Proc. of the Sochi State University, 3, (2010)

9. R. Soubrier, Planification aménagement et loisir [Planification aménagement et loisir] (2000)

10. Ye. N. Ilyina, Management of transport services (1997) 